\title{
Innovation Through Global Collaboration: A new Source of Competitive Advantage (A Study of Nigerian Breweries PLC)
}

Ann Ogbo

University of Nigeria, Enugu Campus, Nigeria

Origho Oscar Japheth

University of Nigeria, Enugu Campus, Nigeria

Wilfred I Ukpere

Department of Industrial Psychology \& People Management, Faculty of Management, University of Johannesburg, South Africa

Doi:10.5901/mjss.2014.v5n1p709

Correspondence author's E-mail: wilfredisiomaukpere@gmail.com

\begin{abstract}
Recent studies on innovation portray traditional approaches to innovation, wherein firms focus solely on their centralized Research and Development team in their pursuit and creation of innovation, as fast becoming outdated; bringing about the need to rethink the way firms managed innovation. This study was motivated by the need to understand the strategies and practices used by firms that have achieved greater success in their collaborative innovative efforts, and how this gave them a competitive advantage, using Nigerian Breweries Plc., as a case study. The research objectives are to: ascertain ways of measuring and developing innovation capabilities for business growth; provide an insight into the concept of global innovative collaboration and how it leads to organizational efficiency; and find out how an effective collaborative network can enhance innovativeness as a springboard for attaining competitive advantage. The research design adopted was the survey method. Primary data were collected using the questionnaire; our hypotheses were tested using the Chi-square, and our respondents comprise of the Management staff, and other category of workers at Nigerian Breweries Plc., which resulted in the following findings: that Nigerian Breweries Plc. was able to achieve efficiency and an immense growth in business by developing adequate collaborative innovative capabilities which have positive impact on the competitive advantage of the organisation. Therefore, the effective collaborative innovative network is the springboard of Nigerian Breweries Plc.'s attainment of competitive advantage; and a corporate collaborative innovation environment helps reinforce and amplify employee morale, build leadership and career opportunities by helping employees work better together. It was concluded that, collaborative innovation is an effective and efficient way to achieve competitive advantage. It is recommended that organisations should, critically assess their collaborative innovation strategies alongside those of other players in preparing for collaboration, tactfully address the issue of trust, focus on efficient use of firm's resources, and continually foster an organisational climate that promotes the processes of collaborative innovation.
\end{abstract}

Keywords: Innovation, Global Collaboration, Competitive Advantage, Strategies

\section{Introduction}

The generation of new ideas and their commercialization has traditionally been done internally, and firms rarely resorted to sharing innovative results, believing that this could adversely affect their ability to generate competitive advantage (Chesbrough, 2003: 36). This is a reflection of an old ideology held by monolithic multinational that creates value in a closed hierarchy and trade secrets, hinged upon, the take industry rule No.1, namely 'Don't share your proprietary data' (Don and Anthony, 2007: 11). However, recently firms are moving to a more collaborative approach to business, and this is shaped constantly by forces such as globalisation, the intensity of technological change and a shift towards crossborder industrial activities (Gassmann, 2006: 224).

It can be deduced from the views above, that it is now an imperative for any organisation having an edge over its competitors to diffuse its efforts outside its traditional research and development units. Leading firms today are basically 
exploring more channels to innovation; usually through an organized open innovation platform/network of collaborators outside the firm's traditional people and facilities (PWC Global CEO Survey, 2006: 14).

It is on this premise that this study explored the developments in innovation conceptualisation and competitive advantage, and how innovation capabilities of a firm can be measured and developed. It also provided an insight into the concept of global collaboration and how an effective global collaboration network can enhance innovativeness in business as a springboard for attaining competitive advantage.

\section{Objectives of the study}

The main objective of this study is to create a thorough understanding of how effectively and efficiently global collaboration can bring about innovation that gives a firm competitive advantage. To achieve this, the following subobjectives of the study will be considered

- $\quad$ To ascertain ways of measuring and developing innovative capabilities, in shaping organisational learning regarding business growth.

- $\quad$ To provide an insight into the concept of global innovative collaboration and how this knowledge can help organisations achieve efficiency.

- $\quad$ To find out how an effective collaborative network can enhance innovativeness in business as a springboard for attaining competitive advantage.

\section{Conceptualisation of developments in innovation and competitive advantage: (The Dichotomous Innovation Frameworks)}

Innovation means different things to different people. Studies by Lan (2006: 106) observes a pattern where innovation has been viewed from a dichotomous lens or framework, with each model or concept having its own acquisition channels, realization paths, and integration requirements and consequences. The dichotomous frameworks include:

- Radical and incremental innovation: This reflects the different impacts of innovation on business and the different knowledge foundation deployed. An incremental innovation builds squarely on the established knowledge base by introducing relatively minor changes to the existing products or services (Henderson and Clark cited in Lan. 2006:106-108). A radical innovation on the other hand, involves methods and materials that are novel to the innovator and others (Schumpeter cited in Lan. 2006:106-108).

- Product and process innovation: This originated from the possible different functions of innovation. Product innovation aims to create new functionalities of a product or a service, while process innovation aims to improve the production or delivery of a product (Abernathy and Utterback cited in Lan. 2006:106-108). There is a different degree of openness between them. Product innovation can be proprietary, while process innovation is comparatively open (Freeman cited in Lan. 2006:106-108).

- Architecture and modular innovation: Architectural innovation is the innovation in which the components of a product are linked together innovatively, while the core-design concepts and basic knowledge underlying the components are untouched. Modular innovation can be a replacement of analogue with digital telephones. It is an innovation that changed a core design concept without changing the product's architecture (Henderson and Clark, 1990: 15).

- Technology and business innovation: Technology innovations involve both product and process innovation and continuously change the link between innovators and their environment (Roberts, 2002: 22). In contrast to technology innovation, business innovation focuses on changing the link between an enterprise and a value chain, the structure of an organisation, the market segments that an enterprise is aiming at, and the method of doing business (Markides cited in Lan. 2006:106-108).

- Disruptive and sustainable innovation: Sustainable innovation improves the performance of established products in the domain that mainstream customers in major markets have historically valued. Therefore, sustainable innovation reinforces the landscape of competition (Christensen cited in Lan. 2006:106-108). 
Disruptive innovations bring to the market a very different value proposition than had been available previously. Due to its different nature, the impacts of disruptive innovation are two-fold. One is that it precipitates the failure of established enterprises. The other is that it fosters start-ups which take up the majority share of an emerging market. In doing so, disruptive innovation changes the landscape of competition (Christensen, 1997: 51).

One striking thing about the innovation frameworks above is that they focus mainly on product and process enhancement. Compared with what is currently in place, which is characterised today's globalised business terrain, it is observed, that the aspects of business such as customer relationship, job development, people development, market development, global synergy, information, communication technology, which all shape and influence competition, were not taken into consideration by the dichotomous frameworks.

However, a new innovation conceptualisation brought about by global collaboration has emerged. It is one that opens its doors to the world, co-innovates with everyone, especially customers; shares resources that were previously closely guarded; harnesses the power of mass collaboration; and behaves not as a multi-national, but as something new: a truly global business (Don and Anthony, 2007: 16). This new innovation concept, namely global innovation collaboration by its very nature is an all-encompassing and eclectic innovation model which embraces all of the above earlier mentioned dichotomous innovation frameworks. It is characterised by a high degree of openness and flexibility which makes it more suitable for today's rapidly evolving business terrain.

\section{Developments of the concept of competitive advantage}

The term competitive advantage has evolved from the comparative advantage theory by the classical economist, David Ricardo, which was centred on primary production assets. By 1985, as society and market advanced, Michael porter developed the concept of competitive advantage with focus on cost leadership and differentiation in product (Wikipedia, 2013). However, Treacy and Wiersema (1995: 24) offered a generic framework for gaining competitive advantage. In their framework, competitive advantage is gained through product leadership, operational excellence and customer intimacy.

Competitive advantage has also been hinged on performance that is, a firm experiences competitive advantages when its actions in an industry or market create economic value and when few competing firms are engaging in similar actions (Barney, 2002: 9). Competitive advantage will mean that organisations possess resources and capabilities that are superior to that of its competitors, thus enabling it to deliver superior value to customers (Porter, 2004: 38). These are sweeping forces in today's business environment which drives competition, as well as rapidly transform traditional approaches to competition. These forces, brought about by globalisation and changes like: increasing volatility in market position, ubiquity of information, blurred company and industry boundaries, growing concern about the social and ecological environment and changing organisational structures make the competition hyper and more intense (BCG Analysis, 2009: 2).

Porter's work on competitive advantage had focused mainly cost leadership and differentiation. The business environment of today and the changes introduced by globalisation were not captured by porter's bases for competitive advantage which invariably, will require some form of advancement. The Boston Consulting Group introduced as supplements to the concept of competitive advantage, six dimensions of advantages which are the bases for new approaches that companies will use in order to compete in the future. 
Figure 2.1: Six New Bases of Advantage Supplement Traditional Ones

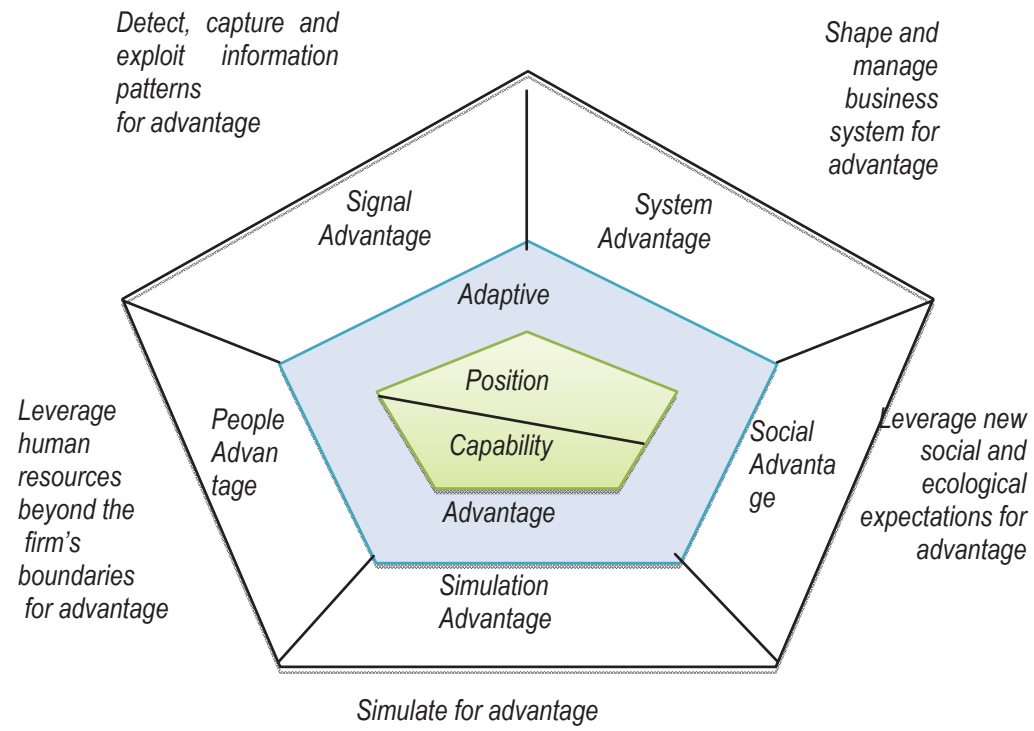

Source: (BCG analysis, 2009:2).

The above figure is explicated below as follows:

Signal Advantage: Given the voluminous and dynamic nature of information available in today's environment, to gain signal advantage will require organisation to focus on the right information, extract relevant signals, process them rapidly and coordinate organisational behaviour to suit such environmental changes, because this same information is simultaneously available to competitors (BCG analysis, 2009:2).

System Advantage: This entails knowing how to, and being able to push operational activities outside the company without benefiting competitors as well as designing strategies for or within networks of companies without reliance on strong control mechanisms (BCG analysis, 2009:3).

Social Advantage: This usually accrues from an organisation's concern for social equity and ecological sustainability expressed through well-coordinated and established corporate social responsibilities as this goes on to curtail possible consumer boycotts, unfavourable regulations and restrictions on freedom to operate (BCG analysis, 2009:3).

Simulation Advantage: A company with simulation advantage decreases the costs and increases the yield of experimentation by tapping consciously into the actual economic behavioural patterns of consumers through modulation of variables such as pricing, design and placement to test consumer response (BCG analysis, 2009:3).

People Advantage: This comes from decentralising an organisation's innovation management by giving room for frequent and effective use of initiative by the company's workforce. This further amplifies creativity and fosters the creation of a highly motivated and autonomous workforce (BCG analysis, 2009:3).

Adaptive Advantage: To gain an adaptive advantage, an organisation will have to renew and sharpen its quest for sustainable competitive advantage by taking cognizance of the unpredictability of today's environment and limits of deductive analysis. To do this, it will have to effectively unite reflection with execution as well as adequately balance deduction with experimentation (BCG analysis, 2009:2).

As traditional strategies become less relevant, companies must supplement them with adaptive advantages supported by further advantages relating to signals, systems, social values, simulation and people empowerment, in order to succeed in a constantly changing and unpredictable business environment (Martin and Michael, 2009:1).

\section{Measuring Innovation Capabilities}

Several authors have presented various models for measuring innovation. The Diamond Innovation Model was 
propounded by Tidd, Bessant and Pavitt (cited in Dalia, 2011: 12). The model takes a look into some of the areas where management can look to evaluate or assess it innovation capabilities. It is a five dimensional assessment model which looks at strategy, process, organisation, linkages and learning, which are discussed below:

- $\quad$ Strategy: This dimension focuses on three areas, namely does the firm have a well-managed strategic planning process in place? Is innovation appreciated by the entire organisation? Is it incorporated within the corporate strategy of the firm and has the firm put in place mechanisms that will effectively implement the corporate strategy? (Tidd et al, 2005:21).

- $\quad$ Process: This dimension considers the robustness and flexibility of the firm's new product development process and whether it brings the attention to everyone involved to the customer's need (as opposed to just marketing focusing on the customer's need). In this dimension, the firm's ability to manage its internal processes is also considered (Dalia, 2011: 12).

- Organisation: In this dimension, two major areas are considered, namely, does the organisational structure encourage, rather than stifle innovation through effective top-down, bottom-up and lateral communication within the firm? Has management put in place a mechanism or system that encourages employees to bring forth new ideas? Tidd et al (cited in Dalia 2011: 12).

- $\quad$ Linkages: In this dimension, the focus is on the firm's ability to create healthy relationships with external entities such as suppliers, customers and the academia, firms from other industries, specialists, individuals as well as competitors, with a look or focus on the potential of these links to provide knowledge/information to the firm (Tidd et al, 2005: 22).

- Learning: Four major areas are considered in this dimension. What is the firm's performance and level of commitment to the training and development of its employees, does the firm have the ability or what is the firm's ability scale in being able, to gather knowledge/information from its linkages, does the firm have the ability to learn from its successes and failures, does the firm have the ability to share these learning to the entire organisation (Tidd et al, 2005: 22).

Figure 2.2: The diamond measurement model

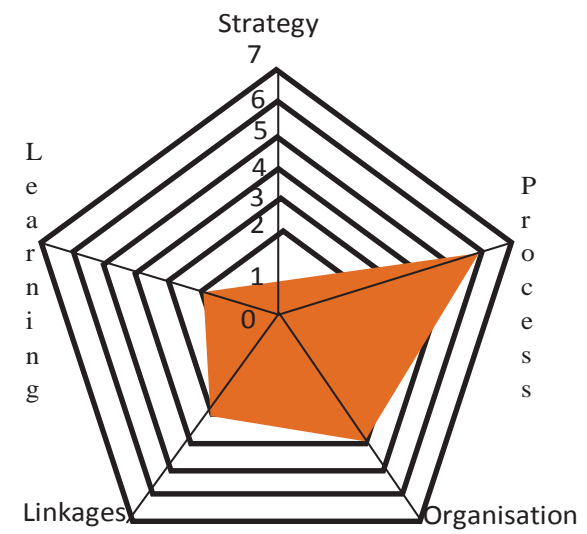

Diamond A

Example of a firm that needs to foster innovation in many dimensions

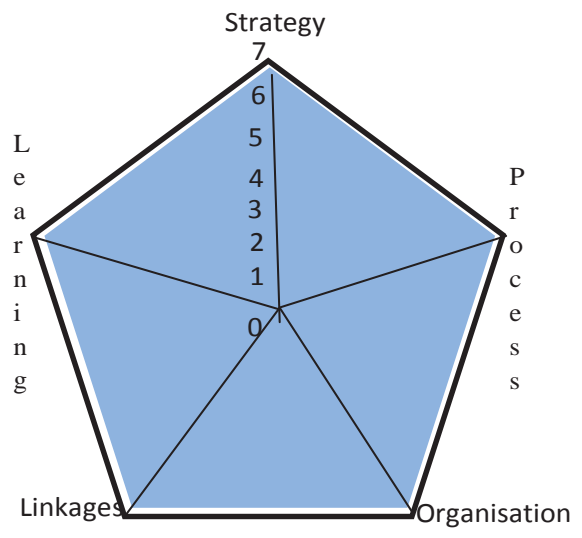

Diamond B

Example of a highly innovative firm

Source: Technology innovation and entrepreneurship centre (2011: 12). 
Diamond $\mathrm{A}$, shows that the firm being represented has an average performance in innovation measured along process and organisation dimensions and a very low innovation performance along the dimensions of linkages, learning and strategy, which is measured using a scale of ' 0 ' to ' 7 '. It therefore entails that the firm strive and apply concerted efforts to create a favourable and healthy innovative relationship with other firms, facilitate the training and development of employees to establish a knowledge driven workforce, establish a well-managed strategic planning process, flexibility in management of internal processes, and an organisational structure that encourage innovation.

On the other hand, diamond B, shows that the firm depicted by the figure, has a high innovation performance level when measured along the dimensions of strategy, process, organisation, linkages and learning. Thus it is expected that the firm will have to promote continued sustainability and maintenance of this innovation capability and performance level.

\section{Developing innovation capabilities}

Benn and Danny (2001: 388) provide an innovation capability model below that could help management to ensure that the firm's innovation development process does not destroy the firm's value or possibly make it bankrupt. The boxes below show areas that focus management should look into when developing innovation capabilities.

Figure 2.3: Innovation Capability Development Model

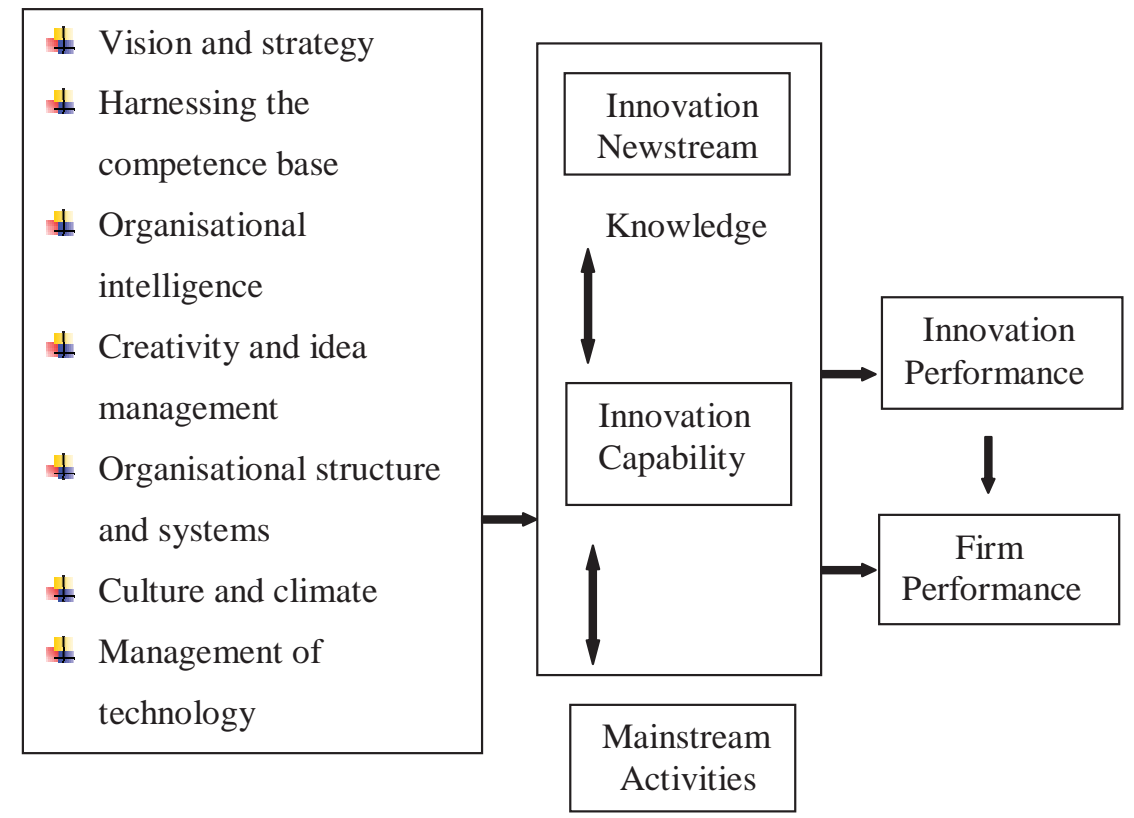

Source: (Benn and Danny, 2001: 388)

The above figure is discussed as under:

\section{1) Vision and strategy}

A critical step in developing innovation capabilities entails establishing a good link and articulation between vision, strategic direction and innovation (Benn and Danny, 2001: 389).

\section{2) Harnessing the competence base}

This entails having ability to correctly and effectively direct resources to where they are required and has long been recognised as critical to innovation success. Important variables to consider in harnessing an organisation's competence 
base include resource management, variety of funding channels, innovation champions, and E-business (Burgelman and Maidique, 1988: 141)

\section{3) Organisational intelligence}

Organisational intelligence has been defined as "the capability to process, interpret, encode, manipulate and access information in a purposeful, goal-directed manner, so it can increase its adaptive potential in the environment in which it operates" (Glynn, 1996: 1088). Organisational intelligence is primarily about learning from customers and learning about competitors.

\section{4) Creativity and idea management}

Creativity operates along a continuum. Organisations need to encourage creativity right along this continuum and at all levels. Creativity requires divergent thinking of what may be unrealised, unproven or untested. It may be knowledgedriven (how do we apply new knowledge?) or vision-driven (this is our goal, what new knowledge do we need?). Creativity may be viewed as the process of generating ideas (Benn and Danny, 2001: 392).

\section{5) Structure and system}

Successful innovation requires an optimal overall formal business structure. Unless this structure and its resulting processes are conducive to a favourable environment, other components of the innovation system are unlikely to succeed (Burgelman and Maidique, 1988: 143).

\section{6) Culture and climate}

An appropriate culture and climate within the organisation is also vitally important to innovation success. It will require management to have tolerance to ambiguity by willing to take risks; investing at empowering employees; institutionalise a little innovation by providing employees with time, funding, facilities and a creative environment; promote and reward cross-functional, cross-hierarchical, cross-cultural and cross-technological exchange of information and knowledge (Benn and Danny, 2001: 385).

\section{7) Management of technology}

The management of technology is crucial to today's organisation. The shift toward external networks and leveraging the entire corporate knowledge base has meant we are more concerned with the management of technology within the overall organisation rather than research and development per se (Fusfeld cited in Benn and Danny, 2001: 397). A number of authors have developed "technological competence audits" allowing firms to assess their technological capabilities, needs and possibilities against overall business objectives (Bessant and Coombs cited in Benn and Danny, 2001: 396).

It can be deduced from the discussions above that to achieve sustainable innovation outcomes as the engine for effective, functional collaboration and business performance organisations will have to consciously develop and invest in these aspects of innovation capability, individually and collectively.

\section{Insight into the concept of global innovation collaboration}

Global innovation collaboration entails accessing globally dispersed knowledge, leveraging new capabilities and sharing risk with partners aimed at providing firms with the relevant innovation, agility and cost effectiveness required to compete successfully in todays networked economy (Allan et al, 2007: 3). Unlike the dichotomous innovation frameworks discussed in preceding sections, it is a much more sophisticated skill to create new sources of value and innovation capabilities.

It also involves significant use of external parties outside the people within the organisation to develop ideas capable of improving stakeholders' value and meeting customers' expectations; it is basically about bringing the outside (an organisations public) in, with the internal environment keeping a large percentage of its potential that is, not getting the inside to unlock the full potential it has (Gianluigi, 2012: 4).

From an economic standpoint, global collaboration entails a cost-driven switch from internal to external input supply, and thus reflects an efficiency imperative. The goal is typically to capitalize on the superior efficiency of partners from international organisations with respect to specialized aspects of business. This owes to the fact that usually, 
individual collaborators do not possess the internal resources and wherewithal to work entirely on their own within a specific business or project domain (Sen and MacPherson, 2009: 22).

Global innovation collaboration subsumes the dichotomous innovation models making it more comprehensive with far reaching impacts on firms operations. Its all-encompassing and flexible nature helps to foster a symbiotic business relationship, which further enhances an organisation's innovative ability in proffering better and feasible solutions to the problems of the emergent global village and in designing products that meet the expectations of customers.

Forms in which global innovation collaboration exist include working with partners on collaborative/international projects, shared expertise, establishing potential 'customers', stakeholder engagement, joint applications for funding, etc., as well as involving physical activities like phone communication, e-mail communication, group communication, exchanging letters and memos, face to face meetings with internal colleagues, face to face meetings with external partners, virtual meetings, etc. (Rob, 2007: 11).

Other common forms/tools used for collaboration activities include: one-to-one email, or one-to-many email (that is, multiple recipients), e-mail discussion lists, teleconferencing, videoconferencing, shared file space and access to documents, shared calendars, mobile access to email, diary, collaborative document editing, shared/project workspace (combining calendar, file space, contacts), interactive communication with customers, etc. (Avanade, 2010: 5).

Over the years this innovation framework has been powered majorly by the increasing influence of globalisation, as well as some other drivers which include:

- $\quad$ Declining long-term sourcing deals for inputs.

- $\quad$ Rising level of competition.

- Industry convergence.

- $\quad$ Rapidly changing business environment.

- $\quad$ Changing values and expectations of stakeholders.

- $\quad$ Complexity of product technology.

- $\quad$ Competition convergence and decline collaboration costs.

- $\quad$ Growing product maturity, etc. (David and Roberts, 2007: 5-6).

There are seven guidelines that management of companies can follow to obtain optimum value-based innovation benefits from their collaboration with other firms. This guideline is aimed at helping managers to steer around the pitfalls, which earlier had beset organisations. It has been formulated to also help managers realize more of their business potential and to measurably enhance their capability to collaborate while gaining positive impacts on the company's product and processes (Julio et al, 2009: 85). The seven keys to collaborative innovation success according to Julio et al., (2009: 85-89) are:

1) Define the project's strategic context as part of the selection process:

2) Select boundary spanning project managers with three key attributes.

3) Share with the team the vision of how collaboration can help the company.

4) Invest in long-term relationships.

5) Establish strong communication linkage with your partners team:

6) Build broad awareness of the project within the company.

7) Support the work internally both during the contract and after, until the research can be exploited

The above will also support effective collaboration network.

\section{Effective Collaboration Network: A springboard for the attainment of Competitive Advantage}

Over the years, firms in their approach to gaining competitive advantage have sometimes emphasised economies of scale and position and at other times capabilities and competencies. Regardless of this shifts in focus, it is fast becoming a fact that collaboration can become the best strategy for attaining competitive advantage. For many organisations which have continuously applied collaborative measures to achieve innovation and enhanced competitive market position, successes has always been their result (BCG-analysis, 2009: 4). 
An effective collaboration can enhance an organisation's innovation as well improve its competitive position in its industry in the following ways:

1) Competitive strategy: Collaborative networks can change the bases of competition in an industry to align with the innovative abilities of members of such network. This is basically the competitive strategy, which IBM used when it teamed with the Open Source movement to a certain extent, as a competitive gambit against Microsoft (David and Robert, 2007: 8).

2) Simulation advantage: Simulation that is, ability to decrease cost and increase the yield of experimentation as well as better tap into the economic behaviours of consumers which further helps the firm to modulate price, design and placement while testing consumers' responses; by co-operating with and sharing information with globally dispersed firms, collaborating partners can better solve problems and get things done through learning about and gaining an appreciation for the needs, interests and capabilities of their collaborators, participants can optimise a solution that works for the network as a whole (David and Robert, 2007: 9).

3) People development: Collaborative models foster contributions from most suitable and motivated talent. Where mechanisms exist to reward contributions on the basis of merit, the best is more likely to rise to the top. This often means that the more participants in a network, the better (BCG analysis, 2009:3)

4) Cost efficiency: Governance is cheaper and productivity goes up. When interests are aligned, participants often work smarter and harder, and police themselves properly both individually and collectively. Engaged participants (customers, partners, suppliers) are more loyal. Budgets for participant retention and replacement can be reduced (David and Robert, 2007: 9).

5) Differentiation: Since there is pull of ideas and knowledge, as well divergent views to a particular problem or need, collaborators are able to develop a product that is complex and difficult for imitators to copy. Usually what leading firms do is that they combine the information and ideas they get from other participants, with their own home knowledge and unique capabilities to produce something novel in nature. Most times it could be that participants get ideas which have already been tested and was successful in a particular country, and has the potential of success in the participants' home country or terrain. This further drives superior performance in innovation as well opportunities and prestige, as the cost of possible failure of such innovation is avoided (Allan, 2007: 14).

6) Wide access to information (signal advantage): Global collaboration networks widen the opportunity, ability to signal trends which aid focus on, and extraction of relevant information, and access to key resources from the environment; which have the potential to maintain or enhance competitive advantage (Gulati et al cited in Allan et al 2007; BCG analysis, 2009: 3).

7) Compatibility (system advantage): Customers, employees, and all other stakeholders are expecting products and services offered by their firm to possess the highly upheld standards in quality and design which in most cases are expected to be able to gain international acceptance. Global collaboration in this instance creates a system advantage that provides an enabling environment for product or service compatibility with international standards and best practice (IBM, 2008: 9).

8) Alternative Enterprising (New value opportunities): Another area global collaboration confers on organisations competitive advantage is in helping to do this differently and in a more diversified way, better than the traditional way and more effectively and efficiently than competitors (Cole, 2005: 8). It also provides organisations with new streams of business and value creation opportunities. An effective collaboration network helps to build capabilities, and in turn, create options to pursue strategies that cannot be replicated by competitors. For these firms, collaboration had become a springboard for the attainment of competitive advantage (Allan et al, 2007: 16). See figure below. 
Figure 2.4: Collaborative Capabilities Create New Business Opportunities

\section{Top-down planning process}

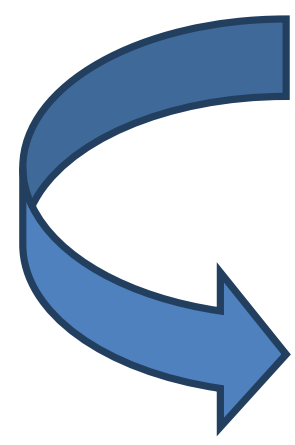

Collaboration

Network

(Capabilities)

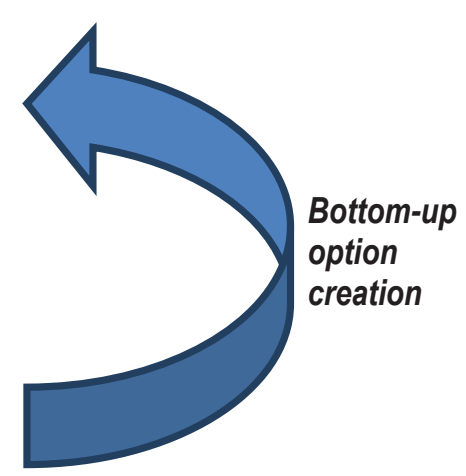

Source: (Allan et al, 2007: 16).

9) Superior performance: Superior performance in business operation is easily achieved through global collaboration, as it puts together various advantage like: lower costs, superior capabilities, contextual knowledge, ability to develop strategies in dealing with the unpredictability of today's environment, ability to push activities outside the firm without benefiting competitors, focus on social responsibility advantage; ability to garner or harness the creativity of a more autonomous and highly motivated globally dispersed workforce and network; etc. (Allan et al, 2007: 5), and (Sen and MacPherson, 2009: 45). See table below:

Table 2.1: The Benefits from Collaboration

\begin{tabular}{lll}
\hline Lower Costs & Superior Capabilities & Contextual Knowledge \\
\hline Low labour cost & Rapid access to capacity & Market access \\
Low materials cost & Technical know-how & Supplier relationships \\
Low suppliers cost & Process expertise & Institutional ties \\
Low infrastructure cost & Domain knowledge & Government connections \\
\hline
\end{tabular}

Source: (Allan et al, 2007: 5).

\section{Building an Effective Collaboration Network}

In today's business environment, learning to collaborate creatively and effectively with people across cultures has become a vital skill (Roy cited in Michael, 2012: 1). The business environment of today is characterized by a rising pace of technological change and fierce competition which means that firms cannot maintain capabilities in all potentially relevant technical and market areas. The ability of firm's to absorb knowledge gained through participation in an external network is critical to successful innovation (Cohen and Levinthal, cited in Allan et al 2007:13).

This invariably, has led to increasing research by firms to find how to develop exchange relationships with units and individuals beyond the traditional boundaries of the firm. Allan et al (2007: 4-15) provide a three (3) step guide on how to build an effective collaboration network. These steps are:

a) Develop a strategy for collaboration: This entails putting into consideration the "3Cs" of global collaboration: cost, capabilities and context. 
Figure 2.5: The 3Cs of a Global Collaboration Strategy

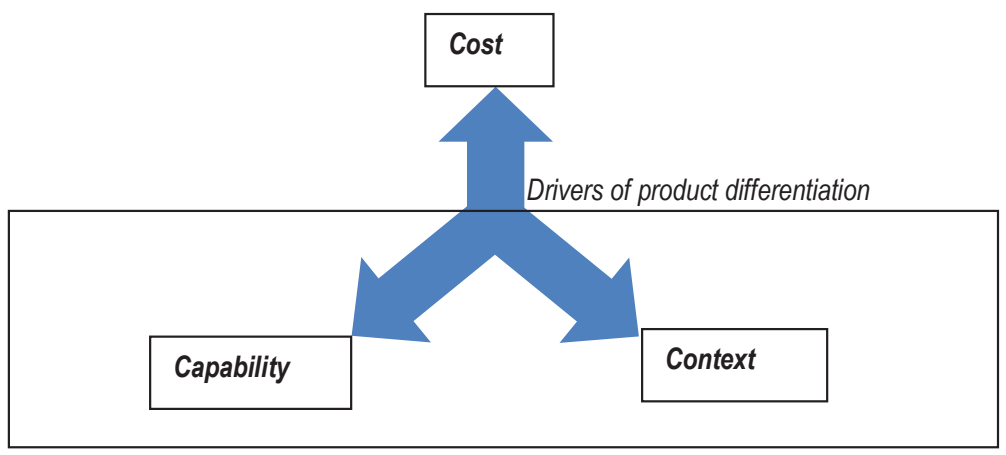

Source: (Allan et al, 2007: 4).

b) Organize for collaboration: Organising for collaboration will require management to take on actions and activities which reflect a common shift in values towards a more open and flexible approach. As such, it is expedient that an organisation leverages partner's intellectual property (IP) and focus on the cost and speed advantages. In addition to this, management should develop mechanisms for partners to access their own IP, in a way that facilitates collaboration but ensures the protection of competitive assets while it applies and shares with its partners, newly developed IP in a mutually beneficial fashion as long as the uses are not competitive (Allan et al, 2007: 8-11).

Build collaborative capabilities: The final area separating leading firms from others in their collaboration efforts was willingness to invest in developing "collaborative capabilities." All too often, firms assumed that their existing employees, processes and infrastructure were capable of meeting the challenge of collaboration. However, successful collaboration does not just happen, since it is a skill that must be learned (Jeffrey and Janice, 2010: 12). There are four areas successful firms have usually targeted investments in namely people, process, platforms and programs. These investments were typically funded outside the budgets of individual projects, given that few projects can justify the levels of infrastructure needed to perform well on their own. In essence, leading firms made a strategic decision to invest in collaborative capabilities and sought to leverage these investments across projects and over time. These areas are referred to as the: "Four Pillars" of collaborative capability (Allan et al, 2007:11).

Figure 2.6: The Four Pillars of Collaborative Capabilities

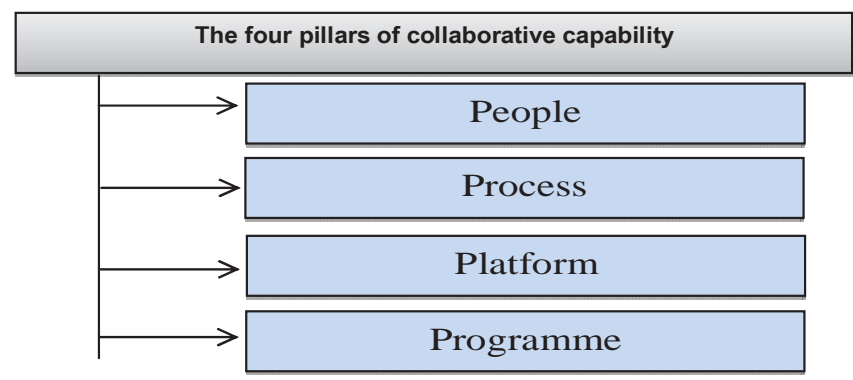

Source: (Allan et al, 2007: 12).

\section{Research design \& method of data analysis}

This is a completed research work designed to give an overview of how global innovation collaboration serves as a new source of competitive advantage, with a study on Nigerian Breweries Plc. innovation processes and mechanism. The research was conducted using the descriptive survey method, wherein questions were drawn up in questionnaire and administered to staff of Nigerian Breweries Plc. The chi-square was adopted to analyse the data since it tests the 
statistical significance of association. The chi-square is a non-parametric test that tries to establish the independence between variables in cross sectional studies.

\section{Findings}

Organisational innovation has generally been considered a confidential and internal activity. Some firms however, have now recognised that innovative ideas can emerge from anywhere and it is more beneficial to engage others in collaborative innovation. Global innovation collaboration is fast becoming perceived as essential for business success. Basically, it links people together thereby reducing the delay involved in connecting, sharing, understanding and making business use of information. It also changes the business culture and the way people work, as well as the way they think about how they go about their work. Throughout this study, adequate care was taken to examine how innovation through global collaboration gives Nigerian Breweries Plc. competitive advantage. From the study it was found that:

1. Nigerian Breweries Plc. was able to achieve efficiency through global innovation collaboration.

The table below gives statistical data obtained from the survey conducted.

Table 3.1: Response to Global innovation collaboration significantly affects Nigerian Breweries Plc.'s organisational efficiency in a positive way

\begin{tabular}{lccccc}
\hline Response & Mgt. Staff & Brewery line worker & Other category & Total & $\%$ \\
\hline Strongly Agree & 44 & 49 & 8 & 101 & 33 \\
Agree & & 100 & 85 & 185 & 60 \\
Indifferent & - & 14 & 9 & 23 & 7 \\
Disagree & - & - & - & - & - \\
Strongly Disagree & - & - & - & - & - \\
Total & 44 & 163 & 102 & 309 & 100 \\
\hline
\end{tabular}

Source: Field Survey, 2013.

The table 3.1 above shows that $33 \%$ of the respondents strongly agreed that global innovation collaboration significantly affects Nigerian Breweries PIc.'s organisational efficiency in a positive way, $60 \%$ of the respondents agreed that global innovation collaboration significantly affects Nigerian Breweries Plc.'s organisational efficiency in a positive way, while $7 \%$ of the respondents were indifferent that global innovation collaboration significantly affects Nigerian Breweries Plc.'s organisational efficiency in a positive way.

Table 3.2: Computation of the Chi-square $\left(\mathrm{X}^{2}\right)$

\begin{tabular}{llllll}
\hline $\mathbf{S} / \mathbf{n}$ & $\mathbf{f}_{\mathrm{o}}$ & $\mathbf{f}_{\mathrm{e}}$ & $\left(\mathrm{f}_{\mathrm{o}}-\mathrm{f}_{\mathrm{e}}\right)$ & $\left(\mathbf{f}_{\mathrm{o}}-\mathrm{f}_{\mathrm{e}}\right)^{\mathbf{2}}$ & $\frac{\left(\mathbf{f}_{\mathrm{o}}-\mathbf{f}_{\mathrm{e}}\right)^{2}}{\mathrm{f}_{\mathrm{e}}}$ \\
\hline 1 & & & & & 61.01 \\
2 & 44 & 14.38 & 29.62 & 877.34 & 26.34 \\
3 & 0 & 26.34 & -26.34 & 693.79 & 3.70 \\
4 & 0 & 3.70 & -3.70 & 13.69 & 0.34 \\
5 & 49 & 53.28 & 4.28 & 18.32 & 0.06 \\
6 & 100 & 97.59 & 2.41 & 5.81 & 0.29 \\
7 & 14 & 12.13 & 1.87 & 3.49 & 19.26 \\
8 & 8 & 33.34 & -25.34 & 642.12 & 0.38 \\
9 & 85 & 61.07 & 23.93 & 572.64 & $\mathbf{1 2 0 . 6 4}$ \\
Total & 9 & 7.59 & 1.41 & 1.99 & \\
\hline
\end{tabular}

Source: Field Survey, 2013.

The computed value of the chi-square $\left(X^{2}\right)=120.64$ is greater than the critical value of 9.49 . This implies that that there is a significant relationship between global innovation collaboration and organisational efficiency of Nigerian Breweries PIc. 
2. Nigerian Breweries Plc. was able to achieve immense growth in business by developing adequate collaborative innovation capabilities.

Table 3.3: Response to Nigerian Breweries PIc.'s innovation capabilities has significantly and continually enhanced her business growth over the years

\begin{tabular}{lccccc}
\hline Response & Mgt. Staff & Brewery line worker & Other category & Total & $\%$ \\
\hline Strongly Agree & 35 & 71 & 23 & 129 & 42 \\
Agree & 9 & 68 & 62 & 139 & 45 \\
Indifferent & - & 24 & 17 & 41 & 13 \\
Disagree & - & - & - & - & - \\
Strongly Disagree & - & - & - & - & - \\
Total & 44 & 163 & 102 & 309 & 100 \\
\hline
\end{tabular}

Source: Field Survey, 2013.

The table 3.3 above shows that $42 \%$ of the respondents strongly agreed that Nigerian Breweries Plc.'s innovation capabilities have significantly and continually enhanced her business growth over the years, $45 \%$ of the respondents agreed that Nigerian Breweries Plc.'s innovation capabilities have significantly and continually enhanced her business growth over the years, while $13 \%$ of the respondents were indifferent that Nigerian Breweries Plc.'s innovation capabilities have significantly and continually enhanced her business growth over the years.

Table 3.4: Computation of the Chi-square $\left(\mathrm{X}^{2}\right)$

\begin{tabular}{llllll}
\hline S/n & $f_{o}$ & $f_{e}$ & $\left(f_{o}-f_{e}\right)$ & $\left(f_{o}-f_{e}\right)^{2}$ & $\frac{\left(f_{o}-f_{e}\right)^{2}}{f_{e}}$ \\
\hline 1 & 35 & 18.37 & 16.63 & 276.56 & 15.05 \\
2 & 9 & 19.8 & -10.8 & 116.64 & 5.89 \\
3 & 0 & 5.84 & -5.84 & 34.11 & 5.84 \\
4 & 71 & 68.05 & 2.95 & 8.70 & 0.13 \\
5 & 68 & 73.32 & 5.23 & 27.35 & 0.37 \\
6 & 24 & 21.63 & 2.37 & 5.62 & 0.26 \\
7 & 23 & 42.58 & -19.58 & 383.38 & 9 \\
8 & 62 & 45.88 & 16.12 & 259.85 & 5.66 \\
9 & 17 & 13.53 & 3.47 & 12.04 & 0.89 \\
Total & & & & & 43.09 \\
\hline
\end{tabular}

Source: Field Survey, 2013.

Since the computed value of the chi-square $\left(X^{2}\right)=43.09$ is greater than the critical value of 9.49 . This implies that that there is a significant relationship between innovation capabilities and business growth of Nigerian Breweries Plc.

3. Collaborative innovation capabilities impacted positively on the competitive advantage of Nigerian Breweries Plc.

Table 3.5: Innovation through collaboration positively impacted and increased Nigerian Breweries PIc.'s competitive advantage

\begin{tabular}{lccccc}
\hline Response & Mgt. Staff & Brewery line worker & Other category & Total & $\%$ \\
\hline Strongly Agree & 44 & 99 & 26 & 169 & 55 \\
Agree & - & 60 & 56 & 116 & 37 \\
Indifferent & - & - & 15 & 15 & 5 \\
Disagree & - & 4 & 5 & 9 & 3 \\
Strongly Disagree & - & - & - & - & - \\
Total & 44 & 163 & 102 & 309 & 100 \\
\hline
\end{tabular}

Source: Field Survey, 2013. 
The table 3.5 above shows that $55 \%$ of the respondents strongly agreed that Innovation through collaboration has positively impacted and increased Nigerian Breweries Plc.'s competitive advantage, 39\% of the respondents agreed that Innovation through collaboration has positively impacted and increased Nigerian Breweries PIc.'s competitive advantage, while $6 \%$ of the respondents were indifferent about the impact of Innovation through collaboration, on Nigerian Breweries Plc.'s competitive advantage.

Table 3.6: Computation of the Chi-square $\left(\mathbf{X}^{2}\right)$

\begin{tabular}{llllll}
\hline S/n & $f_{0}$ & $f_{e}$ & $\left(f_{o}-f_{e}\right)$ & $\left(f_{o}-f_{e}\right)^{2}$ & $\frac{\left(f_{o}-f_{e}\right)^{2}}{f_{e}}$ \\
\hline 1 & & & & & 16.43 \\
2 & 44 & 24.1 & 19.9 & 396.01 & 16.5 \\
3 & 0 & 16.5 & -16.5 & 272.25 & 2.1 \\
4 & 0 & 2.1 & -2.1 & 4.41 & 1.3 \\
5 & 0 & 1.3 & -1.3 & 1.69 & 0.12 \\
6 & 99 & 89 & 10 & 100 & 7.9 \\
7 & 60 & 61.2 & -1.2 & 1.44 & 0.10 \\
8 & 0 & 7.9 & -7.9 & 62.41 & 15.91 \\
9 & 4 & 4.7 & -0.7 & 0.49 & 8.18 \\
10 & 26 & 55.8 & -29.8 & 888.04 & 20.82 \\
11 & 56 & 38.3 & 17.7 & 313.29 & 1.52 \\
12 & 15 & 4.9 & 10.1 & 102.01 & 91.9 \\
Total & 5 & 2.9 & 2.1 & 4.41 & \\
\hline
\end{tabular}

Source: Field Survey, 2013.

Since the computed value of the chi-square $\left(X^{2}\right)=91.9$ is greater than the critical value of 12.59 . This implies that that there is a significant relationship between innovation through global collaboration and the competitive advantage of Nigerian Breweries Plc.

\section{Summary of findings}

1. Nigerian Breweries Plc. was able to achieve efficiency through global innovation collaboration.

2. Nigerian Breweries Plc. was able to achieve immense growth in business by developing adequate collaborative innovation capabilities.

3. Collaborative innovation capabilities impacted positively on the competitive advantage of Nigerian Breweries Plc.

4. The springboard of Nigerian Breweries Plc.'s attainment of competitive advantage is an effective collaborative innovation network.

5. lastly, is the fact that a corporate collaborative innovation environment helps reinforce and amplify employee morale, build leadership and career opportunities by helping employees work together and better.

\section{Conclusion \& recommendations}

Based on the result of our analysis of the collaborative approach to innovation employed by Nigerian Breweries Plc., we can conclusively say that innovation through global collaboration is an effective and efficient way to achieve competitive advantage. It therefore implies that only those firms that are able to identify key technologies, develop relevant innovation capabilities and foster an innovation culture and business strategy that support collaboration, will at the end of the day achieve superior performance in business over other industry players, in today's globalised market that is increasingly dependent on knowledge-sharing. Hence, innovation through global collaboration is known to have a positive impact on the bottom-line of an organisation as well as foster internal 'collective intelligence' in solving business issues more effectively and efficiently. To benefit optimally from this, the following recommendations are worth pondering:

1. Management should develop a system that fosters proper management of collaboration relationships; from time to time critically assess its innovation strategy alongside those of other players so as to enable the firm 
prepare adequately for collaboration as well as develop a vision for collaborative innovation and an open innovative mind-set.

2. Management should also tactfully address the issue of trust by acquiring cultural code switching skill, as well as imbibe the best practices of innovation.

3. Adequate focus on efficient resource utilisation and management.

4. Management should consistently foster an organisational climate that promotes the processes of collaborative innovation, through periodic training and orientation on the developments and vagaries of innovation concepts, skills continuity and a well-organised and effective line of communication.

\section{References}

Abereijo, I. O. Ilori, M. O. Taiwo, K. A. and Adegbite, S. A. (2007), 'Assessment Of The Capabilities For Innovation By Small And Medium Industry In Nigeria', African Journal of Business Management; 1(8).

Alan, Mac, Theodore, F. Peter, B. and Patrick, K. (2007), Innovation through Global Collaboration: A New Source of Competitive Advantage, Boston, Harvard Business School Press.

Aluko, M. Odugbesan, O. Gbadamosi, G. and Osuagwu, L. (2011), Business Policy and Strategy, Nigeria, Longman.

Avanade, (2010), Global Survey of Collaboration in the Enterprise.

Barney, Jay. B. (2002), Gaining and Sustaining Competitive Advantage, $\quad$ Addison, Wesley.

BCG Analysis, (2009), The Adaptive Imperative, Boston, BCG Inc.

Benn, L and Danny, S (2001), 'Developing Innovation Capability in Organisations: A Dynamic Capabilities Approach', International journal of innovation management; $5(3)$.

Bhutta, M.K.S. and Reyes, P.M. (2006), 'A framework for Global Implementation of Effective Customer Response (ECR)', Int. J. Management Practice; 2(1).

Burgelman, RA. and Maidique, MA (1988), Strategic Management of Technology and Innovation, Homewood, Illinois-Irwin.

Chesbrough, H.W. (2003), Open Innovation: The New Imperative for Creating and Profiting from Technology, Boston, Harvard Business School Press.

Christensen, C. (1997), The Innovator's Dilemma, Boston, Harvard Business School Press.

Chukwu B. I. (2007), Fundamental Business Statistics, Enugu, Horse-throne concept Inc.

Cole, E. (2005), Strategies for Competitive Advantage, Department of Agricultural and Applied Economics, University of Wyoming.

Dalia, G. (2011), How to Measure Organisational Innovativeness? Innovation Support Department, Egypt, Technology Innovation and Enterpreneurship Center (TIEC).

David, T. and Robert, S. (2007), Collaborate and Innovate: A New World of Sourcing, Nigeria, PWC Inc.

Don, T. and Anthony, D. (2007), 'Innovation in the Age of Mass Collaboration', Businessweek - wikinomics series.

Gassmann, O. (2006), 'Opening Up the Innovation Process: Towards an Agenda', $R$ and D Management Review; 36(3), NESTA.

Gianluigi, C. (2012), Case:Open Innovation In The Biorefinery Industry. <http://www.innovationmanagement.se/2012/12/07/ Case-OpenInnovation-in-the-Biorefinery-industryl>

Glynn, MA, (1996), 'Innovative Genius: A Framework For Relating Individual And Organisational Intelligences To Innovation', Academy of Management Review; 21(4).

Henderson, R.M. and Clark, K. (1990), 'Architectural Innovation: The Reconfiguration of Existing Product Technologies and The Failure of Established Firms', Administrative Science Quarterly; Vol 35.

IBM (2008), The New Collaboration: Enabling Innovation, Changing The Workplace, USA, New Orchard.

Jeffrey, S. and Janice, T. (2010), 'Collaborative Networks are the Organization:An Innovation in Organization Design and Management', Vikalpa, the Journal for Decision Makers; 35(1).

Julio, AP. Edward, SC. Edward, MG. and William, AL. (2010), 'Best Practices For Industry-University Collaboration', MIT Sloan Management Review; 51(4).

Lan, P (2006), 'A Framework for Innovation Decision Making in the Internet Age', Int. Journal of Management and Decision Making; 7(1).

Martin, R. and Michael, S. D. (2009), The New Bases of Competitive Advantage: BCG Perspectives, Boston, BCG Inc.

Michael, B. (2012), Collaborating Across Cultures, HBS Working Papers. <hbswk.hbs.edu/item/6687.html>

Nigerian Breweries Plc. (2012), About Us. Available from: <http://www.nbplc.com/our_company.html>

Nigerian Breweries Plc. (2012), Annual Report and Account.

Nigerian Breweries Plc. (2012), Winning With Nigeria! Internal NB/Trade Census 2011, Google.

Porter, M. E. (2004), Competitive Advantage: Creating and Sustaining Superior Performance, USA, the Free Press.

Pricewaterhousecoopers-PWC. (2006), Global CEO Survey, Nigeria, PWC Inc.

PWC, (2009), Global CEO Survey, Nigeria, PWC Inc.

Rob, A. (2007), A Study of Tools for Collaboration and Partnership Working in Business and Community Engagement, USA, Netskills.

Roberts, E. B. (2002), Innovation: Driving Product, Process, and Market Change, San Francisco, Jossey-Bass. 
Sen, A. and MacPherson, A. (2009), 'Outsourcing, External Collaboration, And Innovation Among US Firms In The Biopharmaceutical Industry', The Industrial Geographer, 6(1).

Tidd, J, Bessant, J, and Pavitt, K, (2005), Managing Innovation: Integrating Technological, Market and Organisational Change, Great Britain, John Wiley and Sons Inc.

Treacy, M. and Wiersema, F. (1995), The Discipline of Market Leaders, Wesley, Addison.

Wikipeadia, (2013), Developments in the Concept of Competitive Advantage. 